\title{
Serum homocysteine and folate concentrations among a US cohort of adolescents before and after folic acid fortification
}

\author{
Daniel A Enquobahrie ${ }^{1,2, *}$, Henry A Feldman ${ }^{3,4}$, Deanna H Hoelscher ${ }^{5}$, Lyn M Steffen 6 , \\ Larry S Webber ${ }^{7}$, Michelle M Zive ${ }^{8}$, Eric B Rimm $9,10,11,12$, Meir J Stampfer $9,10,11,12$ \\ and Stavroula K Osganian ${ }^{3,4}$ \\ 'Cardiovascular Health Research Unit, University of Washington, 1730 Minor Avenue, Suite \#1360, Seattle, \\ WA 98101, USA: ${ }^{2}$ Department of Epidemiology, University of Washington, Seattle, WA, USA: ${ }^{3}$ Children's \\ Hospital, Boston, MA, USA: ${ }^{4}$ Department of Pediatrics, Harvard Medical School, Boston, MA, USA: ${ }^{5}$ University \\ of Texas School of Public Health, Houston, TX, USA: 'Division of Epidemiology and Community Health, \\ University of Minnesota School of Public Health, Minneapolis, MN, USA: ${ }^{7}$ Department of Biostatistics, Tulane \\ University School of Public Health and Tropical Medicine, New Orleans, LA, USA: ${ }^{8}$ Community Pediatrics \\ Division, University of California San Diego, San Diego, CA, USA: ${ }^{9}$ Department of Medicine, Harvard Medical \\ School, Boston, MA, USA: ${ }^{10}$ Department of Epidemiology, Harvard School of Public Health, Boston, MA, USA: \\ ${ }^{11}$ Department of Nutrition, Harvard School of Public Health, Boston, MA, USA: ${ }^{12}$ Channing Laboratory, Brigham \\ and Women's Hospital, Boston, MA, USA
}

Submitted 7 November 2011: Final revision received 2 April 2012: Accepted 4 May 2012: First published online 4 July 2012

\begin{abstract}
Objective: We assessed serum homocysteine (tHcy) and folate concentrations among US adolescents before and after fortification of cereal-grain products with folic acid, and associations with demographic, behavioural and physiological factors.

Design: Observational study conducted among participants of a randomized trial. Setting: The Child and Adolescent Trial for Cardiovascular Health (CATCH) study. Subjects: Adolescents ( $n$ 2445) in grades 8 (pre-fortification, mean age 14 years) and 12 (post-fortification, mean age 18 years).

Results: Average serum concentrations of tHcy, folate and vitamin $\mathrm{B}_{6}$ increased by $17 \%, 16 \%$ and $14 \%$, respectively, while serum concentrations of vitamin $\mathrm{B}_{12}$ decreased by $11 \%$ post-fortification. Folic acid fortification provided, on average, an additional intake of $118 \mu \mathrm{g}$ folate/d. Male sex $(P<0 \cdot 0001)$ and white race $(P=0 \cdot 0008)$ were associated with significantly greater increases in tHcy concentration, while increases in BMI $(P=0 \cdot 006)$ and serum folate concentration $(P<0 \cdot 0001)$ were associated with significant decreases in tHcy concentration. Female sex $(P<0 \cdot 0001)$, non-smoking $(P<0 \cdot 0001)$, use of multivitamins $(P<0 \cdot 0001)$ and higher dietary intake of folate $(P=0 \cdot 001)$ were associated with significantly greater increases in serum folate concentrations. From grade 8 to grade 12, the upward age trend in serum tHcy concentration was uninterrupted in its course $(P>0.50)$; whereas serum folic acid concentration showed a downward trend that incurred a discrete jump upward ( $17 \%$ higher; $P<0 \cdot 0001)$ with fortification. These trends differed significantly for males $v$. females $(P<0 \cdot 001$ for interaction).

Conclusions: Fortification had a significant impact on improving folate status but not serum tHcy concentrations among US adolescents.
\end{abstract}

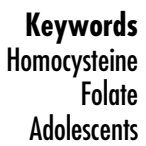

Cardiovascular risk factors in childhood and adolescence are related to disease risk in adults ${ }^{(1,2)}$. Thus, a better understanding of risk factor(s) relationships and disease pathogenesis in youth may aid in prevention and early treatment $^{(1,2)}$. Observational studies and some randomized trials suggest that homocysteine (tHcy) is a continuous, independent and modifiable risk factor of CVD, especially stroke $^{(3-7)}$. Elevation of tHcy as a result of dietary, genetic, metabolic and hormonal factors ${ }^{(8)}$ may result in vascular wall damage ${ }^{(9,10)}$, smooth muscle and connective tissue proliferation $^{(9,10)}$, procoagulant activity ${ }^{(9,10)}$, inflammatory response $^{(11)}$ and oxidative stress ${ }^{(12)}$.

An intermediate in methionine metabolism, tHcy is metabolized via a vitamin $\mathrm{B}_{6}$-dependent conversion to cysteine or a folate- and vitamin $\mathrm{B}_{12}$-dependent remethylation to methionine ${ }^{(13)}$. Serum folate, vitamin $\mathrm{B}_{6}$ and 
vitamin $\mathrm{B}_{12}$ concentrations are inversely associated with serum tHcy concentrations ${ }^{(14,15)}$, and dietary supplementation of these vitamins reduces tHcy concentrations ${ }^{(14,16)}$. In particular, folate appears to be the most important dietary determinant of tHcy concentration ${ }^{(17,18)}$ and a high intake of dietary folate/folic acid has been associated with lower concentrations of tHcy in adults, independent of other dietary or lifestyle factors ${ }^{(19-22)}$. Furthermore, high blood concentration of folate or intake of folate/folic acid has also been associated with a reduced risk of CVD and stroke in some studies ${ }^{(23)}$.

The US Food and Drug Administration mandated that cereal-grain products be fortified with $140 \mu \mathrm{g}$ folic acid/ $100 \mathrm{~g}$ grain by 1 January $1998^{(24)}$, providing a unique opportunity to examine the effect of folic acid fortification on tHcy concentrations in the general population. Numerous studies in adults have demonstrated that folic acid fortification resulted in increased folate intake, significantly improved serum folate concentrations and decreased circulating tHcy concentrations ${ }^{(14,16,25)}$. In contrast, few studies have investigated the effects of folic acid fortification of food in children and adolescents ${ }^{(26)}$. To date, most studies examining serum tHcy and folate concentrations in children and adolescents have been cross-sectional, based on data collected pre-fortification ${ }^{(27)}$ or post-fortification ${ }^{(28)}$, and compared to reference values. Among an ethnically diverse cohort of youth from the Child and Adolescent Trial for Cardiovascular Health $(\mathrm{CATCH})^{(29,30)}$, we therefore examined changes in serum tHcy and folate concentrations pre- and post-folic acid fortification and associations with demographic, behavioural and physiological factors.

\section{Methods}

\section{Overview of the study}

The subjects for the present analysis were part of CATCH, a trial designed to evaluate the effectiveness of a multicomponent school-based cardiovascular health promotion intervention, described elsewhere in detail ${ }^{(29,30)}$. The main trial (1991-1994) was conducted among students in grades 3 to 5 attending ninety-six public elementary schools (fifty-six intervention and forty control schools) in California, Louisiana, Minnesota and Texas. Following the main trial, two observational studies were conducted that measured physiological and behavioural risk factors in study participants from grades 6 to 8 (1994-1997; pre-fortification) and in grade 12 (2000-2001; post-fortification) ${ }^{(30)}$. The current report is based on analysis of data collected during the grade 8 and grade 12 follow-up assessments.

\section{Study population}

The CATCH study initially recruited 5106 grade 3 students to participate in a risk factor screening at baseline. Of these, 3645 (71\%) participated in risk factor screening at the end of grade 8 when serum tHcy, folate, vitamin $\mathrm{B}_{6}$ and vitamin $\mathrm{B}_{12}$ were first assessed and 2909 (57\%) students participated in the follow-up risk factor screening in grade 12 . Of these students, 2445 attended both grade 8 and grade 12 examinations and provided blood at both examinations. This group constituted the study population for the present report. Students were recruited through schools or direct mailing to their homes. Parental consent was obtained for those under 18 years of age. Written informed consent was obtained from all participants and their parents, respectively. Institutional Review Boards at all four study sites and the coordinating centre at the New England Research Institutes approved the study.

\section{Data collection}

To ensure comparability, data collection methods ${ }^{(29,30)}$ were similar across all time points and during the initial trial. Information on family history of risk factors for CVD and smoking was collected by student completed questionnaires. Dietary history including information on dietary folate intake and dietary supplement use was assessed at grade 12 only using a 149-item self-administered FFQ, the Youth/Adolescent Questionnaire $(\mathrm{YAQ})^{(31)}$, validated for use with children and adolescents aged 9 to 18 years. Examinations were conducted primarily in schools and to a lesser extent in other central community settings and participants' homes (in mobile vans). These examinations were conducted by trained and certified CATCH study staff at the sites. BMI was calculated as weight in kilograms divided by the square of height in metres.

Non-fasting blood samples were collected from each student enrolled in the study as reported elsewhere ${ }^{(30)}$. Briefly, blood was collected via venepuncture in red-top serum separator tubes and allowed to clot for exactly $20 \mathrm{~min}$ at room temperature, then placed directly on crushed ice until centrifugation. All samples were centrifuged 3-4h later at the study centres and serum was placed in $5 \mathrm{~cm}^{3}$ labelled Nalgene Cryule Vials (Nalgene Co., Rochester, NY, USA) and refrigerated until shipment for processing at the Central Laboratory at Miriam Hospital (Providence, RI, USA). Total serum tHcy was measured using the fluorimeteric method of Vester and Rasmussen, except that $20 \%$ methanol by vol. was used in buffer $\mathrm{B}$ in the HPLC procedure ${ }^{(32)}$. Serum folate and vitamin $\mathrm{B}_{12}$ were measured using a solid-phase, no-boil RIA in a commercial kit (Diagnostic Productions Corp., Los Angeles, CA, USA) ${ }^{(33,34)}$. Serum vitamin $\mathrm{B}_{6}$ was measured using a radioassay kit (ALPCO, Windham, NH, USA) that measures the conversion of titrated tyrosine to tyramine by the vitamin $\mathrm{B}_{6}$-dependent enzyme tyrosine decarboxylase ${ }^{(35)}$. The same laboratory methods and assays were used at both time points.

\section{Statistical analysis}

Demographic characteristics and physiological measures in the study sample were summarized pre-fortification 
(grade 8) and post-fortification (grade 12) by percentages, means and standard deviations as appropriate.

Serum tHcy and folate concentration changes between grade 8 and grade 12 were compared according to sex, race, smoking status and multivitamin use. These comparisons were made first without adjustment or statistical testing (means and their standard errors tabulated at grade 8 and grade 12), then by mixed-effects regression analyses. The regression models used change from grade 8 to grade 12 concentrations as the dependent variable. For serum tHcy, each model was adjusted for design factors (CATCH site, school, intervention group); for covariates (sex, race, age at grade 8 , smoking status and multivitamin supplement use at grade 12); for changes (between grade 8 and grade 12) in cardiovascular risk factors (BMI and systolic blood pressure); and for changes (between grade 8 and grade 12) in serum folate, vitamin $\mathrm{B}_{6}$ and vitamin $\mathrm{B}_{12}$. For serum folate, each model was adjusted for design factors (CATCH site, school, intervention group); for covariates (sex, race, age at grade 8 , smoking status and multivitamin supplement use at grade 12); for changes (between grade 8 and grade 12) in BMI; and for grade 12 intakes of dietary folate. These analyses were also conducted on a subset of the cohort that excluded multivitamin and folic acid supplement users. We obtained comparable results using log-transformed and untransformed values and therefore report the latter.

We modelled the inverse relationship between serum tHcy and folate concentrations as a two-segment linear relationship ${ }^{(30)}$, with both variables log-transformed to reduce the influence of extreme values. We used non-linear regression analysis to determine the segment slopes and their junction point separately at grade 8 and grade 12 measurements. Neither segment showed a significant change in slope between the two measurements $(P>0 \cdot 05)$. The change in the folate-tHcy relationship was therefore modelled as a simple translation of the junction point. Age trends in tHcy and folate concentrations were estimated by performing the linear regression of log concentrations $v$. age. Neither trend showed a significant change in slope between the two measurements $(P>0 \cdot 05)$. The grade 8 and grade 12 trends were therefore modelled as parallel, with separate intercepts allowing us to detect any discrete increase or decrease in tHcy and folate concentrations following fortification. These analyses were restricted to non-users of multivitamin and folic acid supplements and were stratified by sex.

All tests were conducted with type I error set at 0.05 for each pairing of dependent and independent variables. The SAS statistical software package version $9 \cdot 1$ was used for all computations.

\section{Results}

The mean age of participants was $14 \cdot 1$ years (range: $10 \cdot 9$ to $16 \cdot 8$ years) at grade 8 (pre-fortification) and $18 \cdot 2$ years (range: $15 \cdot 2$ to $20 \cdot 7$ years) at grade 12 (post-fortification) assessments (Table 1). Males and females were equally represented at both time points. Respondents were more likely to be female or of white race compared with nonrespondents $(50 \cdot 5 \%$ female $v .46 \cdot 1 \%$ female, $P=0 \cdot 0015$ or $74 \cdot 4 \%$ white $v \cdot 64 \cdot 2 \%$ white, $P<0 \cdot 001$, respectively). However, there was no significant difference in the distribution of respondents' and non-respondents' original school intervention condition. The proportion of respondents who reported smoking cigarettes increased from $12 \%$ to $27 \%$ from grade 8 to grade 12 , and the proportion who reported taking a multivitamin remained the same at approximately $23 \%$ of the sample. Average serum concentrations of tHcy, folate and vitamin $\mathrm{B}_{6}$ increased (by 17\%, 16\% and $14 \%$, respectively) while serum concentrations of vitamin $\mathrm{B}_{12}$ decreased (by $11 \%$ ). When calculating folate intakes of students at grade 12 , using the nutrient database values with and without fortification, fortification with folic acid provided, on average, an additional $118 \mu \mathrm{g}$ folate/d, for a total mean folate intake of $359 \mu \mathrm{g} / \mathrm{d}$. We observed similar findings among the sub-cohort that was restricted to non-users of multivitamins or folic acid supplements.

Average serum tHcy concentrations increased from $5 \cdot 28 \mu \mathrm{mol} / 1$ in grade 8 to $6 \cdot 19 \mu \mathrm{mol} / 1$ in grade 12 (Table 2 ). After adjusting for demographic, physiological and behavioural variables, and changes in serum folate, vitamin $\mathrm{B}_{6}$ and vitamin $B_{12}$, the increase in serum tHcy was significantly greater among males compared with females $(1 \cdot 24 \mu \mathrm{mol} / \mathrm{l} v$. $0.59 \mu \mathrm{mol} / 1$, respectively; $P<0.0001)$. Similarly, the increase in serum tHcy was significantly greater among whites compared with blacks $(1 \cdot 01 \mu \mathrm{mol} / 1 v \cdot 0 \cdot 43 \mu \mathrm{mol} / \mathrm{l}$, respectively; $P=0 \cdot 0008)$. Change in BMI showed a small but significant inverse relationship with change in tHcy concentration $\left(0.05 \mu \mathrm{mol} / \mathrm{l}\right.$ decrease in tHcy per $1 \mathrm{~kg} / \mathrm{m}^{2}$ increase in BMI, $P=0 \cdot 006$ ). Change in serum folate concentration was strongly and inversely associated with change in serum tHcy concentration (an average decrease of $0.72 \mu \mathrm{mol} / 1$ in tHcy for every $50 \mathrm{nmol} / 1$ increase in serum folate, $P<0 \cdot 0001)$. Changes in systolic blood pressure, serum vitamin $\mathrm{B}_{12}$ and $\mathrm{B}_{6}$ were not significantly associated with change in serum tHcy concentrations. These results were not substantially different when analyses were restricted to those who did not use multivitamins or folic acid supplements.

Serum folate concentrations increased from $42.6 \mathrm{nmol} / 1$ in grade 8 to $49 \cdot 3 \mathrm{nmol} / 1$ in grade 12 (Table 3 ). In analyses simultaneously adjusted for age, sex, race, current smoking, current multivitamin use and change in BMI, females, current non-smokers and multivitamin users had significantly greater increases in serum folate concentration than males, smokers and multivitamin non-users, respectively $(10 \cdot 8 \mathrm{nmol} / 1$ in males $v .2 .5 \mathrm{nmol} / 1$ in females, $P<0 \cdot 0001 ; 8 \cdot 0 \mathrm{nmol} / 1$ in non-smokers $v \cdot 3 \cdot 1 \mathrm{nmol} / 1$ in smokers, $P<0 \cdot 0001 ; 13 \cdot 2 \mathrm{nmol} / 1$ in multivitamin users $v$. $4 \cdot 8 \mathrm{nmol} / 1$ in non-users, $P<0 \cdot 001)$. Dietary folate intake 
Table 1 Characteristics of the CATCH (Child and Adolescent Trial for Cardiovascular Health) cohort; 2445 students examined at both grade 8 (1996-1997) and grade 12 (2000-2001)

\begin{tabular}{|c|c|c|c|c|}
\hline & \multicolumn{2}{|c|}{ Grade 8} & \multicolumn{2}{|c|}{ Grade 12} \\
\hline & $n$ & $\%$ & $n$ & $\%$ \\
\hline \multicolumn{5}{|l|}{ Sex } \\
\hline Male & 1210 & $49 \cdot 5$ & - & - \\
\hline Female & 1235 & $50 \cdot 5$ & - & - \\
\hline \multicolumn{5}{|l|}{ Race/ethnicity } \\
\hline White & 1820 & $74 \cdot 4$ & - & - \\
\hline Black & 286 & $11 \cdot 7$ & - & - \\
\hline Hispanic & 250 & $10 \cdot 2$ & - & - \\
\hline Others & 89 & $3 \cdot \overline{6}$ & - & - \\
\hline Current smoker & 294 & $12 \cdot 1$ & 669 & $27 \cdot 4$ \\
\hline Multivitamin use & 524 & $22 \cdot 9$ & 550 & $22 \cdot 5$ \\
\hline \multirow[t]{2}{*}{ Folic acid supplement use } & $-t$ & & 118 & $4 \cdot 8$ \\
\hline & Mean & SD & Mean & SD \\
\hline Age (years) & $14 \cdot 1$ & 0.5 & $18 \cdot 2$ & 0.5 \\
\hline $\mathrm{BMl}\left(\mathrm{kg} / \mathrm{m}^{2}\right)$ & $21 \cdot 9$ & $4 \cdot 5$ & $24 \cdot 4$ & $5 \cdot 2$ \\
\hline Systolic blood pressure (mmHg) & 114 & 8 & 116 & 10 \\
\hline Diastolic blood pressure $(\mathrm{mmHg})$ & 56 & 7 & 57 & 8 \\
\hline \multicolumn{5}{|l|}{ Serum concentration, all } \\
\hline Homocysteine $(\mu \mathrm{mol} / \mathrm{l})$ & $5 \cdot 28$ & $1 \cdot 86$ & $6 \cdot 19$ & $2 \cdot 39$ \\
\hline Folate $(\mathrm{nmol} / \mathrm{l})$ & $42 \cdot 6$ & $21 \cdot 5$ & $49 \cdot 3$ & $25 \cdot 7$ \\
\hline Vitamin $\mathrm{B}_{6}(\mathrm{nmol} / \mathrm{l})$ & $48 \cdot 5$ & $49 \cdot 8$ & $55 \cdot 1$ & $63 \cdot 6$ \\
\hline Vitamin $\mathrm{B}_{12}(\mathrm{pmol} / \mathrm{l})$ & 398 & 168 & 356 & 153 \\
\hline \multicolumn{5}{|c|}{ Serum concentration, supplement non-users* } \\
\hline Homocysteine $(\mu \mathrm{mol} / \mathrm{l})$ & $5 \cdot 34$ & $1 \cdot 89$ & $6 \cdot 28$ & $2 \cdot 45$ \\
\hline Folate $(\mathrm{nmol} / \mathrm{l})$ & $39 \cdot 8$ & $17 \cdot 7$ & $45 \cdot 2$ & $21 \cdot 8$ \\
\hline Vitamin $\mathrm{B}_{6}(\mathrm{nmol} / \mathrm{l})$ & $43 \cdot 1$ & $32 \cdot 9$ & $47 \cdot 2$ & $47 \cdot 3$ \\
\hline Vitamin $B_{12}(\mathrm{pmol} / /)$ & 387 & 154 & 349 & 151 \\
\hline \multicolumn{5}{|l|}{ Dietary intake, all } \\
\hline Folate ( $\mu \mathrm{g} / \mathrm{d}$; with fortification) & $-\dagger$ & - & 359 & 165 \\
\hline Folate ( $\mu \mathrm{g} / \mathrm{d}$; without fortification) & - & - & 241 & 125 \\
\hline Vitamin $B_{6}(\mathrm{mg} / \mathrm{d})$ & - & - & $1 \cdot 50$ & 0.68 \\
\hline Vitamin $B_{12}(\mu \mathrm{g} / \mathrm{d})$ & - & - & $6 \cdot 15$ & $4 \cdot 66$ \\
\hline \multicolumn{5}{|l|}{ Dietary intake, supplement non-users* } \\
\hline Folate ( $\mu \mathrm{g} / \mathrm{d}$; with fortification) & $-t$ & - & 348 & 161 \\
\hline Folate ( $\mu \mathrm{g} / \mathrm{d}$; without fortification) & - & - & 232 & 121 \\
\hline Vitamin $B_{6}(\mathrm{mg} / \mathrm{d})$ & - & - & $1 \cdot 47$ & 0.67 \\
\hline Vitamin $B_{12}(\mu \mathrm{g} / \mathrm{d})$ & - & - & $6 \cdot 20$ & $4 \cdot 76$ \\
\hline
\end{tabular}

*Non-users of multivitamins or folic acid supplements, $n 1530$.

tNot determined at grade 8 .

was strongly and positively associated with change in serum folic acid concentration $(1.01 \mathrm{nmol} / 1$ increase in serum folic acid concentration for every $100 \mu \mathrm{g} / \mathrm{d}$ increase in folate intake, $P=0 \cdot 001)$. The differences in demographic and behavioural factors were similar and remained significant after adjusting for total folate intake (which included folic acid from fortification) in grade 12. These results were not substantially different when analyses were restricted to those who did not use multivitamins or folic acid supplements.

The inverse relationship of serum tHcy with serum folate in students not taking multivitamins or folic acid supplements is illustrated in Fig. 1, as modelled by a segmented log-log relationship. In grade 8 , serum tHcy concentrations levelled off above a junction point located at a serum folate concentration of $37 \cdot 8 \mathrm{nmol} / \mathrm{l}$. In grade 12 , the junction point shifted rightward, to a higher serum folate concentration of $51.9 \mathrm{nmol} / 1$ (37\% higher, $P<0 \cdot 0001)$ and upward by a serum tHcy concentration of $0.4 \mu \mathrm{mol} / 1(8 \%$ higher, $P<0.003)$. The upward age trend in serum tHcy (Fig. 2) was uninterrupted in its course between the two measurement periods $(P>0 \cdot 50)$. In contrast, folate concentrations showed a downward trend but incurred a discrete jump upward (17\% higher, $P<0 \cdot 0001$ ) between grade 8 and 12 . Sex-stratified analyses indicated more pronounced trends in males than in females $(P<0.001$ for interaction) for both tHcy concentration $(+3 \cdot 8 \%$ year in males, $P=0.006 v+1 \cdot 4 \%$ year in females, $P=0 \cdot 19)$ and folic acid concentration $(-7 \cdot 1 \% /$ year in males, $P=0.0001 v .-3 \cdot 4 \% /$ year in females, $P=0 \cdot 008)$.

\section{Discussion}

In the present study we found that folic acid fortification was associated with $16 \%$ higher mean serum folate concentrations. It significantly prevented the age-related downward trend in serum folate concentrations among 
Table 2 Serum homocysteine concentration in the $\mathrm{CATCH}$ (Child and Adolescent Trial for Cardiovascular Health) cohort before and after folate fortification

\begin{tabular}{|c|c|c|c|c|c|c|c|c|c|}
\hline \multirow[b]{3}{*}{ Predictor } & \multicolumn{9}{|c|}{ Serum homocysteine $(\mu \mathrm{mol} / \mathrm{l})$} \\
\hline & \multicolumn{2}{|c|}{ Grade 8} & \multicolumn{2}{|c|}{ Grade 12} & \multicolumn{5}{|c|}{ Change from grade 8 to grade $12^{*}$} \\
\hline & Meant & SE & Meant & SE & Mean & SE & Subgroup difference & $95 \% \mathrm{Cl}$ & $P$ \\
\hline All & $5 \cdot 28$ & 0.04 & $6 \cdot 19$ & 0.05 & 0.91 & 0.06 & & & \\
\hline \multicolumn{10}{|l|}{ Sex } \\
\hline Female & $5 \cdot 12$ & 0.05 & $5 \cdot 60$ & 0.06 & 0.59 & 0.08 & $-\ddagger$ & & \\
\hline Male & $5 \cdot 46$ & 0.05 & $6 \cdot 79$ & 0.08 & $1 \cdot 24$ & 0.08 & $0 \cdot 65$ & $0 \cdot 43,0.86$ & $<0.0001$ \\
\hline \multicolumn{10}{|l|}{ Race/ethnicity } \\
\hline White & $5 \cdot 20$ & 0.04 & $6 \cdot 22$ & 0.06 & 1.01 & 0.07 & - & & \\
\hline Black & $5 \cdot 96$ & $0 \cdot 14$ & $6 \cdot 38$ & $0 \cdot 13$ & 0.43 & $0 \cdot 16$ & -0.58 & $-0.92,-0.24$ & 0.0008 \\
\hline Hispanic & $5 \cdot 03$ & $0 \cdot 10$ & $5 \cdot 80$ & $0 \cdot 15$ & $0 \cdot 86$ & $0 \cdot 17$ & $-0 \cdot 15$ & $-0.51,0.21$ & 0.42 \\
\hline \multicolumn{10}{|l|}{ Smoking } \\
\hline Non-smoker & $5 \cdot 27$ & 0.04 & $6 \cdot 09$ & 0.05 & 0.88 & 0.07 & - & & \\
\hline Smoker & $5 \cdot 31$ & 0.08 & $6 \cdot 41$ & $0 \cdot 10$ & 0.99 & $0 \cdot 10$ & $0 \cdot 11$ & $-0.11,0.33$ & $0 \cdot 33$ \\
\hline \multicolumn{10}{|l|}{ Multivitamin use } \\
\hline Non-user & $5 \cdot 30$ & 0.04 & $6 \cdot 26$ & 0.06 & 0.94 & 0.06 & - & & \\
\hline Users & $5 \cdot 23$ & 0.08 & $5 \cdot 88$ & 0.09 & $0 \cdot 81$ & $0 \cdot 11$ & $-0 \cdot 13$ & $-0 \cdot 37,0 \cdot 10$ & $0 \cdot 27$ \\
\hline \multicolumn{10}{|l|}{ Per indicated change in predictor } \\
\hline BMI, $1 \mathrm{~kg} / \mathrm{m}^{2}$ & & & & & -0.05 & 0.02 & & & 0.006 \\
\hline Systolic blood pressure, $5 \mathrm{mmHg}$ & & & & & 0.04 & 0.03 & & & $0 \cdot 20$ \\
\hline Serum folate, $50 \mathrm{nmol} / \mathrm{l}$ & & & & & -0.72 & $0 \cdot 11$ & & & $<0.0001$ \\
\hline Serum vitamin $B_{6}, 50 \mathrm{nmol} / \mathrm{l}$ & & & & & 0.03 & 0.04 & & & 0.48 \\
\hline Serum vitamin $B_{12}, 1000 \mathrm{pmol} / \mathrm{l}$ & & & & & $-0 \cdot 15$ & $0 \cdot 35$ & & & $0 \cdot 67$ \\
\hline
\end{tabular}

${ }^{*}$ From mixed-effects regression analysis, adjusting for age, sex, race, $\mathrm{CATCH}$ site, intervention group, random variation among schools, multivitamin supplement use and smoking in grade 12, and changes between grade 8 and 12 in BMI, systolic blood pressure and serum concentrations of folate, vitamin $B_{6}$ and vitamin $B_{12}$. $P$ tests for non-zero difference in mean serum homocysteine change between indicated subgroup and reference subgroup, or for non-zero change in serum homocysteine per indicated change in predictor.

tUnadjusted.

†Reference group.

Table 3 Serum folate concentration in the $\mathrm{CATCH}$ (Child and Adolescent Trial for Cardiovascular Health) cohort before and after folate fortification

\begin{tabular}{|c|c|c|c|c|c|c|c|c|c|}
\hline \multirow[b]{3}{*}{ Predictor } & \multicolumn{9}{|c|}{ Serum folate $(\mathrm{nmol} / \mathrm{l})$} \\
\hline & \multicolumn{2}{|c|}{ Grade 8} & \multicolumn{2}{|c|}{ Grade 12} & \multicolumn{5}{|c|}{ Change from grade 8 to grade $12^{*}$} \\
\hline & Meant & SE & Meant & SE & Mean & SE & Difference & $95 \% \mathrm{Cl}$ & $P$ \\
\hline All & $42 \cdot 6$ & 0.4 & $49 \cdot 3$ & 0.5 & $6 \cdot 7$ & 0.6 & & & \\
\hline \multicolumn{10}{|l|}{ Sex } \\
\hline Female & $39 \cdot 7$ & 0.6 & $50 \cdot 7$ & $0 \cdot 8$ & $10 \cdot 8$ & $0 \cdot 8$ & $-\ddagger$ & & \\
\hline Male & $45 \cdot 6$ & 0.6 & $47 \cdot 9$ & $0 \cdot 7$ & $2 \cdot 5$ & $0 \cdot 8$ & $-8 \cdot 4$ & $-10 \cdot 4,-6 \cdot 3$ & $<0.0001$ \\
\hline \multicolumn{10}{|l|}{ Race/ethnicity } \\
\hline White & $45 \cdot 0$ & 0.5 & $51 \cdot 4$ & 0.6 & $6 \cdot 7$ & 0.7 & - & & \\
\hline Black & $30 \cdot 7$ & $0 \cdot 7$ & 38.9 & $1 \cdot 2$ & $7 \cdot 2$ & $1 \cdot 7$ & 0.5 & $-3 \cdot 1,4 \cdot 0$ & $0 \cdot 79$ \\
\hline Hispanic & $39 \cdot 4$ & $1 \cdot 0$ & $45 \cdot 7$ & $1 \cdot 1$ & $4 \cdot 6$ & $1 \cdot 8$ & $-2 \cdot 1$ & $-5 \cdot 8,1 \cdot 6$ & $0 \cdot 27$ \\
\hline \multicolumn{10}{|l|}{ Smoking } \\
\hline Non-smoker & $43 \cdot 0$ & 0.5 & $51 \cdot 3$ & 0.6 & $8 \cdot 0$ & 0.7 & - & & \\
\hline Smoker & $41 \cdot 6$ & $0 \cdot 8$ & $44 \cdot 2$ & $0 \cdot 8$ & $3 \cdot 1$ & $1 \cdot 0$ & $-5 \cdot 0$ & $-7 \cdot 3,-2 \cdot 7$ & $<0.0001$ \\
\hline \multicolumn{10}{|l|}{ Multivitamin use } \\
\hline Non-user & $41 \cdot 2$ & 0.5 & $45 \cdot 7$ & 0.5 & $4 \cdot 8$ & 0.6 & - & & \\
\hline Users & $47 \cdot 5$ & $1 \cdot 1$ & $62 \cdot 0$ & $1 \cdot 3$ & $13 \cdot 2$ & $1 \cdot 1$ & $8 \cdot 4$ & $6 \cdot 0,10 \cdot 9$ & $<0.0001$ \\
\hline \multirow{3}{*}{$\begin{array}{l}\text { Per indicated increment in predictor } \\
\text { Change in BMl, grade } 8 \text { to grade } 12,1 \mathrm{~kg} / \mathrm{m}^{2} \\
\text { Dietary folate intake, grade } 12,100 \mu \mathrm{g} / \mathrm{d}\end{array}$} & & & & & & & & & \\
\hline & & & & & $-0 \cdot 17$ & $0 \cdot 19$ & & & $0 \cdot 38$ \\
\hline & & & & & $1 \cdot 01$ & 0.32 & & & 0.001 \\
\hline
\end{tabular}

*From mixed-effects regression analysis, adjusting for age, sex, race, $\mathrm{CATCH}$ site, intervention group, random variation among schools, multivitamin supplement use and smoking in grade 12, dietary folate intake at grade 12 and change between grade 8 and 12 in BMI. $P$ tests for non-zero difference in mean serum folate change between indicated subgroup and reference subgroup, or for non-zero change in serum folate per indicated increment in predictor. tUnadjusted.

‡Reference group.

US adolescents and to a greater extent for females compared with males. Folate intakes at grade 12 were $118 \mu \mathrm{g} / \mathrm{d}$ higher from fortified foods. However, despite the increase in serum folate concentrations, tHcy concentrations increased by $17 \%$ and the age-related increase in serum tHcy concentration reported in other studies ${ }^{(26)}$ 


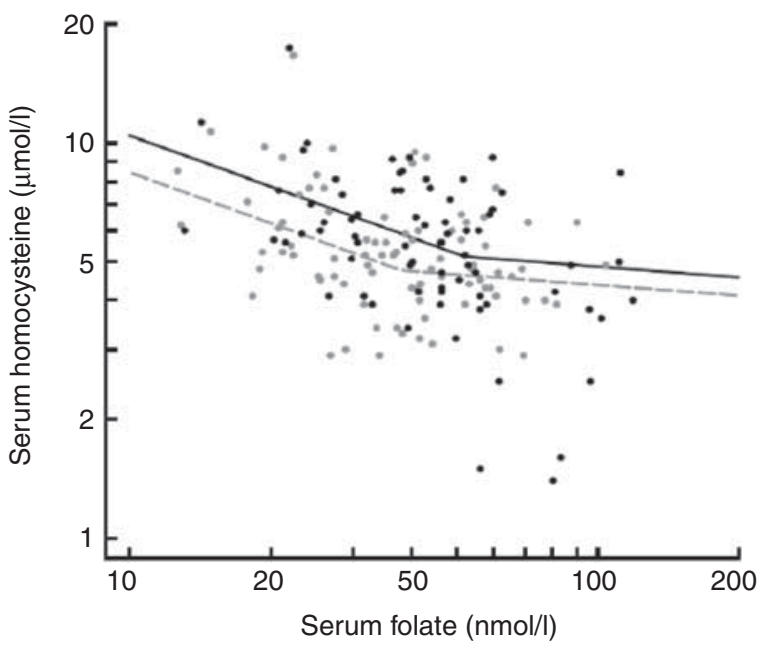

Fig. 1 Inverse relationship between serum homocysteine and serum folate concentrations in the CATCH (Child and Adolescent Trial for Cardiovascular Health) cohort before and after national folic acid fortification. From grade 8 (grey, pre-fortification) to grade 12 (black, post-fortification) the breakpoint of the fitted segmented regression curve shifted rightward, indicating higher folate levels, while the entire curve shifted upward, indicating higher homocysteine levels for a given folate level. Segmented regression curves were fitted to 3152 available joint measurements of homocysteine and folate concentrations, excluding users of multivitamins or supplements. Symbols represent a $5 \%$ random sample of the fitted data

was not affected. The increase in tHcy was more marked for males than females. The inverse relationship between serum folate and tHcy concentrations demonstrated a plateau that levelled off at higher serum folate concentrations post-fortification than pre-fortification $(37 \cdot 8 \mathrm{nmol} / 1$ v. $51 \cdot 9 \mathrm{nmol} / 1$, respectively). We also observed encouraging dietary intakes of folate and vitamins in our adolescent population. Mean intakes observed in our study $\left(359 \mu \mathrm{g} / \mathrm{d}\right.$ for folate, $1.5 \mathrm{mg} / \mathrm{d}$ for vitamin $\mathrm{B}_{6}$ and about $6 \cdot 1 \mu \mathrm{g} / \mathrm{d}$ for vitamin $\mathrm{B}_{12}$ ) were comparable to the RDA for folate $(400 \mu \mathrm{g} / \mathrm{d})$, vitamin $\mathrm{B}_{6}(1 \cdot 3 \mathrm{mg} / \mathrm{d})$ and vitamin $\mathrm{B}_{12}$ $(2 \cdot 4 \mu \mathrm{g} / \mathrm{d})$ for adolescents ${ }^{(36)}$.

Folic acid fortification was introduced by the US Food and Drug Administration in 1998 with the intention of reducing the occurrence of neural tube birth defects in women of childbearing age ${ }^{(37)}$. The level of folic acid fortification was set at $140 \mu \mathrm{g} / 100 \mathrm{~g}$ cereal-grain product and was estimated to increase the intake of folic acid by women of reproductive age by approximately $100 \mu \mathrm{g} / \mathrm{d}^{(38)}$, similar to the $118 \mu \mathrm{g} / \mathrm{d}$ that we observed among US adolescents in the current study. The post-fortification folic acid intake in the present study $(359 \cdot 1 \mu \mathrm{g} / \mathrm{d})$ is much higher in comparison with countries where folic acid fortification has not been mandated. For instance, in Germany, Spain, Sweden, Denmark and the Netherlands, adolescents aged 13-18 years have mean overall folate/folic acid intakes ranging between 203 and $295 \mu \mathrm{g} / \mathrm{d}$ for males and between 192 and $265 \mu \mathrm{g} / \mathrm{d}$ for females ${ }^{(39,40)}$. These values are similar to the mean folate intake we observed in the present study, pre-fortification $(241 \cdot 1 \mu \mathrm{g} / \mathrm{d})$. The higher folate intake post-fortification we observed is also consistent with reports from Canada, where folic acid fortification has been mandated $^{(41)}$. In European countries where folic acid fortification has not been mandated, serum folate concentrations in adolescents have been nearly one-third lower than the concentrations reported in our study ${ }^{(42)}$.

Data from the National Health and Nutrition Examination Surveys have shown that folic acid fortification in the USA is associated with significantly lower plasma tHcy concentrations compared with concentrations before fortification. One study found that folic acid fortification resulted in, on average, a $1.0 \mu \mathrm{mol} / 1$ decrease in tHcy in US children ${ }^{(28)}$. Pfeiffer and colleagues ${ }^{(26)}$ found a small significant decrease in tHcy concentration post-folic acid fortification (1991-1994 v. 1999-2000) among male adolescents but not females, and concentrations then showed small nonsignificant increases during the post-fortification time points (1999-2000 v. 2003-2004). It is possible that once serum folate reaches an optimal concentration, its effect on tHcy concentrations plateau and tHcy concentrations are subsequently determined by other factors such as increasing age. Our findings are comparable to the age-related increase found in the Bogalusa Heart Study ${ }^{(43)}$ which showed an average increase in serum tHcy concentration of $15 \%$ from 12-14 years to 15-17 years. In addition, recent evidence from healthy individuals supplemented with folic $\operatorname{acid}^{(44)}$ and studies examining factors contributing to elevations in tHcy post-fortification ${ }^{(45)}$ suggest that once folate status is optimal, vitamin $\mathrm{B}_{12}$ may become the main nutritional determinant of tHcy concentrations. In addition, increased tHcy has been shown to occur in children with low plasma vitamin $\mathrm{B}_{12}{ }^{(42)}$. It is possible that our finding that tHcy concentrations increased post-fortification may in part be due to decreased vitamin $\mathrm{B}_{12}$.

Folic acid supplementation and fortification have been shown to increase folate intake and serum folate concentrations while decreasing serum tHcy concentrations in different populations ${ }^{(14,46,47)}$. Among adults in the Framingham Offspring study, folate intake increased (approximately $190 \mu \mathrm{g} / \mathrm{d}$ ) and serum tHcy concentrations decreased (approximately 50\%) post-fortification ${ }^{(46)}$. Dose-response relationships between serum tHcy and folate concentrations that level off at higher folate concentrations have also been demonstrated. Among children, plasma folate was negatively associated with plasma tHcy in a dose-dependent fashion only until folate concentrations reached $20 \mathrm{nmol} / \mathrm{l}^{(32)}$. A plateau was observed in our study for the relationship between folate and tHcy at both pre- and post-fortification. Postfortification, this plateau appeared to be reached at higher concentrations of folate and tHcy in our study, which may be related to age trends of increasing tHcy.

Our study findings indicate differences in age-related trends of increase in serum tHcy and decrease in serum 


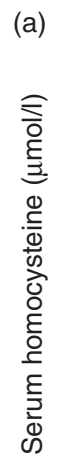

(a)
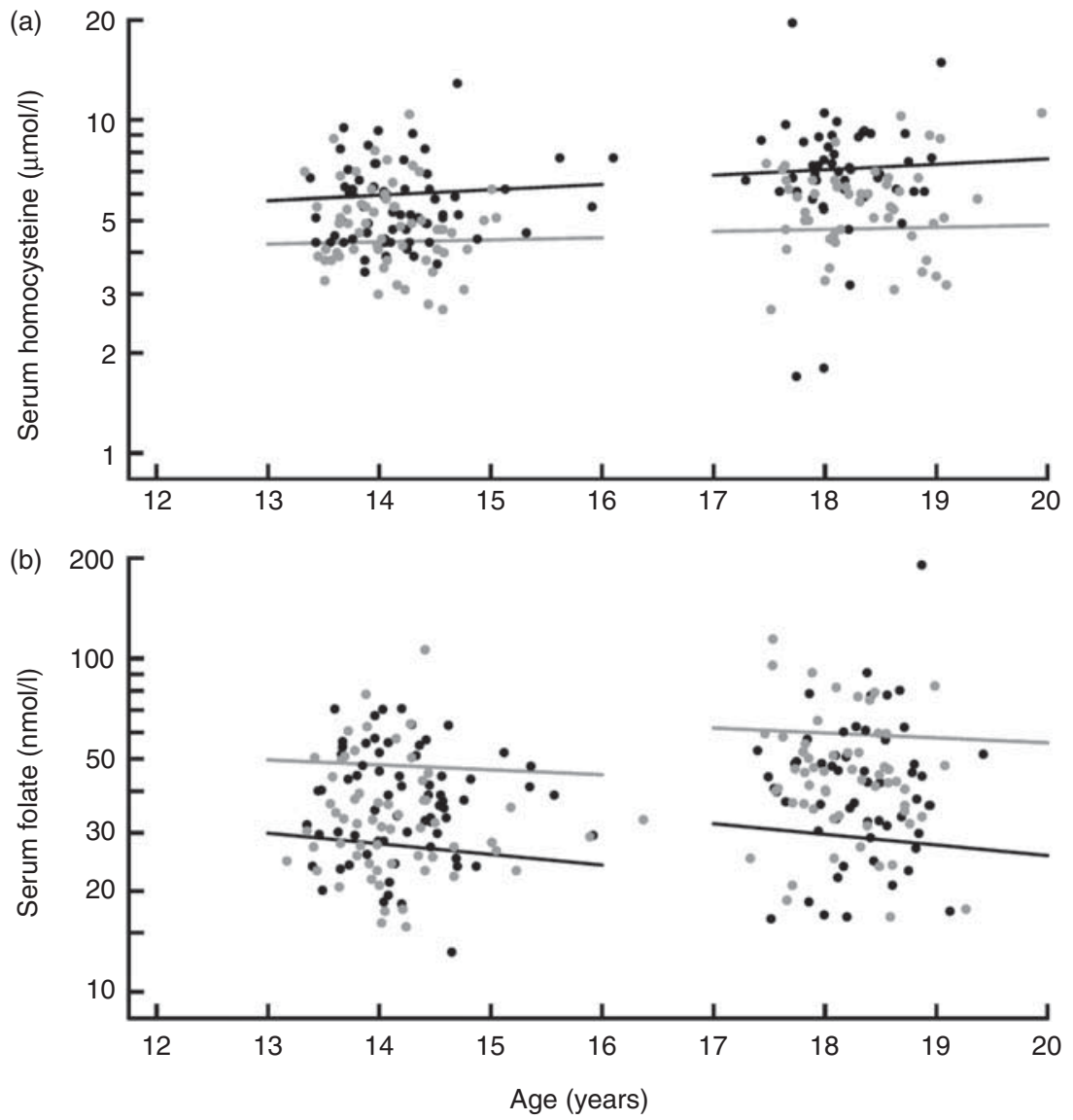

Fig. 2 Trends in serum homocysteine and serum folate concentration in the CATCH (Child and Adolescent Trial for Cardiovascular Health) cohort before and after national folate fortification. (a) For both males (black) and females (grey), the increase in homocysteine levels from grade 8 to grade 12 was a continuation of the within-grade age trend. (b) For both males (black) and females (grey), post-fortification folate levels (grade 12) were significantly higher than would be predicted by continuation of the within-grade age trend at grade $8(P<0.0001$ for discontinuity between grades). Regression lines were fitted to 4620 measurements for the combined grades, excluding users of multivitamins or supplements. Symbols represent a $5 \%$ random sample of the fitted data. For both homocysteine (a) and folate (b), the age trend was significantly steeper for males than females $(P<0.0001$ for age $\times$ sex interaction $)$

folate concentrations among males and females. Differences in remethylation rates ${ }^{(36)}$, lean body mass ${ }^{(37)}$ and hormone-related metabolism ${ }^{(38,39)}$ may account for observed male/female differences in relationships between tHcy, folate and other vitamins. Inconsistencies ${ }^{(16,34,40)}$ in reports of sex-related differences in the literature may be related to differences in vitamin nutritional status, ethnicity composition and other related risk factor differences between study populations.

Some limitations of our study deserve mention. Only $53 \%$ of the original cohort was included in the present study, which may lead to bias. Analyses suggested some significant demographic differences between respondents and non-respondents that may have resulted in inaccurate estimates of changes in tHcy and folate status for gender and race subgroups. Our blood samples were non-fasting. However, an earlier study ${ }^{(27)}$ reported that fasting did not appear to affect tHcy concentrations in participants after adjusting for age and race. Single measurements of tHcy at particular time points do not accurately reflect tHcy variability over time. However, it has been previously demonstrated that an individual's tHcy concentration remains relatively constant over a 30-month period (reliability coefficients: $0 \cdot 66-0 \cdot 82)^{(27)}$. It is also important to note differences in folate equivalents between folic acid used for fortification and dietary folate, as well as limitations in food databases used to determine folate intake. Folic acid taken with food is $85 \%$ bioavailable while food folate is only $50 \%$ bioavailable; thus, folic acid taken with food has $1 \cdot 7$-fold $(85 / 50)$ higher folate equivalents compared with dietary folate (polyglutamate) ${ }^{(48)}$. Current food databases, the majority of which were generated prior to current applications of trienzyme methods, underestimate actual folate content ${ }^{(49)}$. Further, incomplete food tables and seasonal variation in nutrient content or variation in preparation methods may either under- or overestimate actual folate intake ${ }^{(49)}$. However, investigators have reported that estimates of folate intake derived from FFQ are significantly correlated with folate nutritional status among adults ${ }^{(50)}$. Finally, our study lacks a control 
group parallel to the post-folic acid fortification group, making a direct inference not possible. However, our attempt to disentangle age and fortification effects was facilitated by the considerable variability in age among the study population at the two time points. The 2 -year spread within grade, coupled with the large sample size, enabled us to establish the age trend precisely within grade and demonstrate with high statistical significance that the trend was interrupted after fortification for folate but not for tHcy.

\section{Conclusion}

In summary, we have shown that among US adolescents, fortification substantially improved serum folate concentrations and attenuated the age-related decrease in serum folate concentrations, with a greater impact on females than males. Furthermore, fortification resulted in dietary intakes of folate that approached or exceeded the RDA. Future studies are warranted to investigate the significance of these improvements in folate status on clinical outcomes, in the post-fortification era.

\section{Acknowledgements}

This study was supported by grants from the National Heart, Lung, and Blood Institute, National Institutes of Health (R01-HL-66643, U01-HL-3988, U01-HL-39852, U01-HL-39906, U01-HL-39927 and U01-HL-39870). None of the authors had a personal or financial conflict of interest. The authors' contributions were as follows: D.A.E., interpretation, manuscript preparation; H.A.F., study design, statistical analysis, interpretation, manuscript preparation; D.H.H., study design, interpretation, manuscript preparation; L.M.S., study design, interpretation, manuscript preparation; L.S.W., study design, interpretation, manuscript preparation; M.M.Z., study design, interpretation, manuscript preparation; E.B.R., interpretation, manuscript preparation; M.J.S., interpretation, manuscript preparation; S.K.O., study design, statistical analysis, interpretation, manuscript preparation.

\section{References}

1. Morrison JA \& Glueck CJ (1981) Pediatric risk factors for adult coronary heart disease: primary atherosclerosis prevention. Cardiovasc Rev Rep 2, 1269-1281.

2. Hayman LL, Williams CL, Daniels SR et al. (2004) Committee on Atherosclerosis, Hypertension, and Obesity in Youth (AHOY) of the Council on Cardiovascular Disease in the Young, American Heart Association. Cardiovascular health promotion in the schools: a statement for health and education professionals and child health advocates from the Committee on Atherosclerosis, Hypertension, and Obesity in Youth (AHOY) of the Council on Cardiovascular Disease in the Young, American Heart Association. Circulation 110, 2266-2275.
3. Ridker PM, Manson JE, Buring JE et al. (1999) Homocysteine and risk of cardiovascular disease among postmenopausal women. JAMA 281, 1817-1821.

4. Wang X, Qin X, Demirtas H et al. (2007) Efficacy of folic acid supplementation in stroke prevention: a metaanalysis. Lancet 369, 1876-1882.

5. Kahleová R, Palyzová D, Zvára K et al. (2002) Essential hypertension in adolescents: association with insulin resistance and with metabolism of homocysteine and vitamins. Am J Hypertens 15, 857-864.

6. Saposnik G, Ray JG, Sheridan P et al. (2009) Homocysteinelowering therapy and stroke risk, severity, and disability: additional findings from the HOPE 2 trial. Stroke 40, $1365-1372$.

7. Retterstol L, Paus B, Bohn M et al. (2003) Plasma total homocysteine levels and prognosis in patients with previous premature myocardial infarction: a 10-year follow-up study. I Intern Med 253, 284-292.

8. McCully KS (2007) Homocysteine, vitamins, and vascular disease prevention. Am J Clin Nutr 86, issue 5, 1563S-1568S.

9. Berwanger CS, Jeremy JY \& Stansby G (1995) Homocysteine and vascular disease. Br J Surg 82, 726-731.

10. Selhub J \& D'Angelo A (1998) Relationship between homocysteine and thrombotic disease. Am J Med Sci 316, 129-141.

11. Mansoor MA, Seljeflot I, Arnesen H et al. (2004) Endothelial cell adhesion molecules in healthy adults during acute hyperhomocysteinemia and mild hypertriglyceridemia. Clin Biochem 37, 408-414.

12. Loscalzo J (1996) The oxidant stress of hyperhomocysteinemia. J Clin Invest 98, 5-7.

13. Selhub J \& Miller JW (1992) The pathogenesis of homocysteinemia: interruption of the coordinate regulation by S-adenosylmethionine of the remethylation and transsulfuration of homocysteine. Am J Clin Nutr 55, 131-138.

14. Hoey L, McNulty $\mathrm{H}$, Askin $\mathrm{N}$ et al. (2007) Effect of a voluntary food fortification policy on folate, related B vitamin status, and homocysteine in healthy adults. $A m \mathrm{~J}$ Clin Nutr 86, 1405-1413.

15. Shimakawa T, Nieto FJ, Malinow MR et al. (1997) Vitamin intake: a possible determinant of plasma homocyst(e)ine among middle-aged adults. Ann Epidemiol 7, 285-293.

16. Homocysteine Lowering Trialists' Collaboration (1998) Lowering blood homocysteine with folic acid based supplements: meta-analysis of randomized trials. BMJ 316, 894-898.

17. Boushey CJ, Bresford SA, Omenn GS et al. (1995) A quantitative assessment of plasma homocysteine as a risk factor for vascular disease. Probable benefits of increasing folic acid intakes. JAMA 274, 1049-1057.

18. Brattstrom L (1996) Vitamins as homocysteine-lowering agents. J Nutr 126, 4 Suppl., 1276S-1280S.

19. Rasmussen LB, Ovesen L, Bulow I et al. (2000) Folate intake, lifestyle factors, and homocysteine concentrations in younger and older women. Am J Clin Nutr 72, 1156-1163.

20. de Bree A, Verschuren WM, Blom HJ et al. (2001) Association between B vitamin intake and plasma homocysteine concentration in the general Dutch population aged 20-65 y. Am J Clin Nutr 73, 1027-1033.

21. Jacques PF, Bostom AG, Wilson PW et al. (2001) Determinants of plasma total homocysteine concentration in the Framingham Offspring cohort. Am J Clin Nutr 73, 613-621.

22. Clarke R \& Armitage J (2000) Vitamin supplements and cardiovascular risk: review of the randomized trials of homocysteine-lowering vitamin supplements. Semin Thromb Hemost 26, 341-348.

23. Voutilainen S, Virtanen JK, Rissanen TH et al. (2004) Serum folate and homocysteine and the incidence of acute coronary events: the Kuopio Ischemic Heart Disease Risk Factor Study. Am J Clin Nutr 80, 317-323. 
24. Food and Drug Administration (1996) Food additives permitted for direct addition to food for human consumption; folic acid (folacin), final rule. Fed Regist 61, 8797-8807.

25. Jacques PF, Rosenberg IH, Rogers G et al. (1999) Serum total homocysteine concentrations in adolescent and adult Americans: results from the third National Health and Nutrition Examination Survey. Am J Clin Nutr 69, 482-489.

26. Pfeiffer CM, Osterloh JD, Kennedy-Stephenson $\mathrm{J}$ et al. (2008) Trends in circulating concentrations of total homocysteine among US adolescents and adults: findings from the 1991-1994 and 1999-2004 National Health and Nutrition Examination Surveys. Clin Chem 54, 801-813.

27. Must A, Jacques PF, Rogers G et al. (2003) Serum total homocysteine concentrations in children and adolescents: results from the third National Health and Nutrition Examination Survey (NHANES III). J Nutr 133, 2643-2649.

28. Ganji V \& Kafai MR (2005) Population references for plasma total homocysteine concentrations for US children and adolescents in the post-folic acid fortification era. J Nutr 135, 2253-2256.

29. Luepker RV, Perry CL, McKinlay SM et al. (1996) Outcomes of a field trial to improve children's dietary patterns and physical activity. The Child and Adolescent Trial for Cardiovascular Health. CATCH collaborative group. JAMA 275, 768-776.

30. Osganian SK, Stampfer MJ, Spiegelman D et al. (1999) Distribution of and factors associated with serum homocysteine levels in children: Child and Adolescent Trial for Cardiovascular Health. JAMA 281, 1189-1196.

31. Rockett HR, Breitenbach M, Frazier AL et al. (1996) Validation of a youth/adolescent food frequency questionnaire. Prev Med 26, 808-816.

32. Vester B \& Rasmussen K (1991) High performance liquid chromatography method for rapid and accurate determination of homocysteine in plasma and serum. Eur J Clin Chem Clin Biochem 29, 549-554.

33. McNeely M (1984) Folate assay. In Clinical Chemistry, pp. 1402-1406 [LA Kaplan and AJ Pesce, editors]. St Louis, MO: CV Mosby.

34. El Shami AS \& Durham AP (1983) More on vitamin $B_{12}$ results as measured with boil and no-boil kits. Clin Chem 29, 2115-2116.

35. Shin YS, Rasshofer R, Friedrich B et al. (1983) Pyridoxal-5'phosphate determination by a sensitive micromethod in human blood, urine, and tissues; its relation to cystathioninuria in neuroblastoma and biliary atresia. Clin Chim Acta 127, $77-85$.

36. Institute of Medicine, Food and Nutrition Board (1998) Dietary Reference Intakes: Thiamin, Riboflavin, Niacin,
Vitamin $B_{6}$, Folate, Vitamin $B_{12}$, Pantothenic Acid, Biotin, and Choline. Washington, DC: National Academy Press.

37. Anonymous (1992) Recommendations for the use of folic acid to reduce the number of cases of spina bifida and other neural tube defects. MMWR Recomm Rep 41, 1-7.

38. US Food and Drug Administration (1996) Food standards: amendment of standards of identity for enriched grain products to require additions of folic acid. Fed Regist 61, 8781-8797.

39. de Bree A, van Dusseldorp M, Brouwer IA et al. (1997) Folate intake in Europe: recommended, actual and desired intake. Eur J Clin Nutr 51, 643-660.

40. Sichert-Hellert \& Kersting M (2004) Fortifying food with folic acid improves folate intake in German infants, children, and adolescents. J Nutr 134, 2685-2690.

41. Hennessy-Priest K, Mustard J, Keller H et al. (2009) Folic acid food fortification prevents inadequate folate intake among preschoolers from Ontario. Public Health Nutr 12, 1548-1555.

42. van Beynum IM, den Heijer M, Thomas CM et al. (2005) Total homocysteine and its predictors in Dutch children. Am J Clin Nutr 81, 1110-1116.

43. Greenlund KJ, Srinivasan SR, Xu JH et al. (1999) Plasma homocysteine distribution and its association with parental history of coronary artery disease in black and white children: the Bogalusa Heart Study. Circulation 99, 2144-2149.

44. Quinlivan EP, McPartlin J, McNulty H et al. (2002) Importance of both folic acid and vitamin $\mathrm{B}_{12}$ in reduction of risk of vascular disease. Lancet 359, 227-228.

45. Liaugaudas G, Jacques PF, Selhub J et al. (2001) Renal insufficiency, vitamin $\mathrm{B}(12)$ status, and population attributable risk for mild homocysteinemia among coronary artery disease patients in the era of folic acid-fortified cereal grain flour. Arterioscler Thromb Vasc Biol 21, 849-851.

46. Jacques PF, Selhub J, Bostom AG et al. (1999) The effect of folic acid fortification on plasma folate and total homocysteine concentrations. $N$ Engl J Med 340, 1449-1454.

47. Quinlivan EP \& Gregory JF 3rd (2003) Effect of food fortification on folic acid intake in the United States. Am J Clin Nutr 77, 221-225.

48. National Academy of Sciences (1998) Dietary Reference Intakes: Folate, other B Vitamins and Choline. Washington, DC: National Academy Press.

49. Gregory JF 3rd (2001) Case study: folate bioavailability. J Nutr 131, 4 Suppl., 1376S-1382S.

50. Jacques PF, Sulsky SI, Sadowski JA et al. (1993) Comparison of micronutrient intake measured by a dietary questionnaire and biochemical indicators of micronutrient status. Am J Clin Nutr 57, 182-189. 